\title{
Optimization of tool path for uniform scallop-height in ultra-precision grinding of freeform surfaces
}

\author{
Chen Shanshan ${ }^{\mathrm{a}, \mathrm{b}}$, Cheung Chi Fai ${ }^{\mathrm{a} *}$, Zhang Feihu ${ }^{\mathrm{b}}$, Liu Mingyu ${ }^{\mathrm{a}}$ \\ ${ }^{a}$ State Key Laboratory of Ultra-precision Machining Technology, Department of Industrial and Systems Engineering, The Hong Kong Polytechnic University, \\ Hung Hom, Kowloon, Hong Kong \\ ${ }^{b}$ Harbin Institute of Technology, School of mechanical and electrical engineering, Harbin, 730050, China \\ *Corresponding author: benny.cheung@polyu.edu.hk Fax: (852)23625267
}

\begin{abstract}
Freeform surfaces have been widely used in complex optical devices to improve the functional performance of imaging and illumination quality and reduce sizes. Ultra-precision grinding is a kind of ultra-precision machining technology for fabricating freeform surfaces with high form accuracy and good surface finish. However, the complexity and variation of curvature of the freeform surface impose a lot of challenges to make the process to be more predictable. Tool path as a critical factor directly determines the form error and surface quality in ultra-precision grinding of freeform surfaces. In conventional tool path planning, the constant angle method is widely used in machining freeform surfaces, which resulted in non-uniform scallop-height and degraded surface quality of the machined surfaces. In this paper, a theoretical scallop-height model is developed to relate the residual height and diverse curvature radius. Hence, a novel tool path generation method is developed to achieve uniform scallop-height in ultra-precision grinding of freeform surfaces. Moreover, the iterative closest point (ICP) matching method is used to determine the surface form error between the measured surface and the designed surface. Hence, an optimized tool path generator is developed which is experimentally verified through a series of grinding experiments conducted on annular sinusoidal surface and single sinusoidal surface, which allow the realization of the achievement of uniform scallop-height in ultra-precision grinding of freeform surfaces.
\end{abstract}

Keywords: freeform surfaces; ultra-precision grinding; scallop-height; optimization, tool path generation,

\begin{tabular}{|c|c|c|c|c|c|}
\hline \multicolumn{6}{|c|}{ Nomenclature } \\
\hline$N_{s}$ & $\begin{array}{l}\text { Rotational speed of grinding } \\
\text { wheel spindle }\end{array}$ & $R_{w}$ & Workpiece radius & $A$ & $\begin{array}{l}\text { Amplitude of sinusoidal } \\
\text { surface }\end{array}$ \\
\hline$N_{w}$ & $\begin{array}{l}\text { Rotational speed of } \\
\text { workpiece spindle }\end{array}$ & $S$ & Tool path interval & $\varphi$ & Phase angle \\
\hline$R_{s}$ & Wheel radius & $\rho_{w}$ & $\begin{array}{l}\text { Curvature Radius of } \\
\text { workpiece surface }\end{array}$ & $\lambda$ & $\begin{array}{l}\text { Wave length of sinusoidal } \\
\text { surface }\end{array}$ \\
\hline$r_{s}$ & $\begin{array}{l}\text { Nose radius of the grinding } \\
\text { wheel }\end{array}$ & $R_{t}$ & Scallop height & $M$ & $\begin{array}{l}\text { Machining transformation } \\
\text { matrix }\end{array}$ \\
\hline$V_{f}$ & Feed speed & $H$ & Depth of cut & $T$ & Translation matrix \\
\hline$R$ & $\begin{array}{l}\text { Rotation transformation } \\
\text { matrix }\end{array}$ & $Q_{i j}$ & $\begin{array}{l}\text { Points on the Measured } \\
\text { surface }\end{array}$ & $P_{i j}$ & $\begin{array}{l}\text { Points on the Measured } \\
\text { surface }\end{array}$ \\
\hline
\end{tabular}

\section{Introduction}

With increasing demand of optical and photonic manufacturing industries, many types of high-resolution and compact structure of optical components are widely used for digital cameras, solar concentrator, aspectual illumination system and collimators [1-4]. Freeform surfaces can reduce wave front error and optical elements, which are frequently employed to fabricate the units of highperformance optical system [5]. However, machining of the freeform surfaces involved great challenges resulted from the complex curvature variation. Among various ultra-precision machining processes such as single point diamond turning (SPDT), diamond milling, fly cutting, micro-chiseling and ultra-precision diamond grinding, it is interesting to note that the grinding operation is highly capable of machining optical components made of hard and brittle materials than other machining processes due to high efficiency and high accuracy [6].

In machining of freeform surfaces, the $\mathrm{CNC}$ system controls sequential cutting points of the machine tool over the workpiece by an interpolation algorithm and tool trajectory $[7,8]$. The tool path generation is vital for determining the surface quality and machining efficiency, which attracts a lot of research attention. For a three axes machine tool, the tool path generally evolves as an Achimedean spiral from the outmost area to the rotational center, in which a series of interaction points on the spiral are represented by a polar coordinate system according to the rotational angle and feed speed [9,10]. In conventional machining, the constant angle is widely used tool path generation strategy in machining complex surfaces [11-13], which resulted in non-uniform 
surface scallop-height. The outer area of the machined surface is coarser than that of central region of the surface due to a lager arc-length on outer area. Zhou et al. [14] studied the influence of two different tool path generation strategies based on constant rotational angle and constant arc-length, respectively. It is found that constant arc-length was a preferable method to achieve the higher form accuracy.

However, most of research about tool path control method is based on constant arc-length or operation parameters to study the scallop-height generation, the influence of curvature of the machined surface on the scallop-height generation received little attention. In fact, for machining freeform surfaces, the variation of surface curvature resulting in different scallop-heights and form errors of the machined surface. As a result, it is vital to develop a tool path generation strategy to achieve constant scallop-height so as to improve surface accuracy. In this study, relationship between the curvature and scallop-height is analyzed theoretically and a new control strategy for the tool path with variable feed speed is proposed, which can be used to achieve uniform scallopheight in ultra-precision grinding of freeform surfaces.

\section{Theoretical Modelling of scallop-height in ultra-precision grinding}

In ultra-precision grinding, the rotational workpiece traverses across the high-speed spinning wheel to remove redundant materials and create desired surfaces by changing the tool position with respect to the part and feed speed, as shown in Fig.1 (a). The ground surface generation is directly related to the tool path, in which, the grinding wheel moves in an archimedes spiral in $\mathrm{X}-\mathrm{Y}$ plane, as shown in Fig.1 (b).

In ultra-precision grinding of freeform surfaces, the tool trajectory is a spiral around the rotational centre of the workpiece and scallop height on the workpiece surface producing between two adjacent paths is principally determined by the rotational speed of the workpiece, feed speed and curvature radius of the machined surface. The surface curvature resulted in different contacted point refer to the cutting profile of the grinding wheel, which caused the different scallop height on the ground surface. Fig. 2 shows the different geometric relationships among flat surface, convex surface machining and concave surface machining. For grinding flat surface, the tool path interval is easy to be determined, which keeps uniform spacing. However, for machining convex and concave surfaces, the calculation is more complex and the interval spacing is changeable according to the curvature radius.

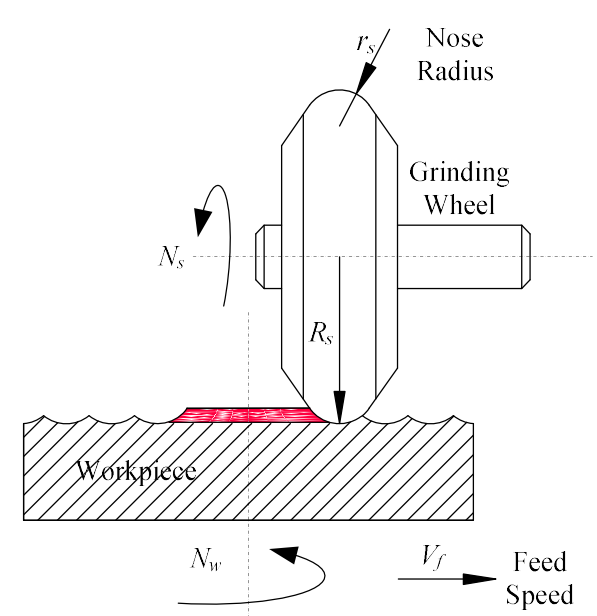

(a)

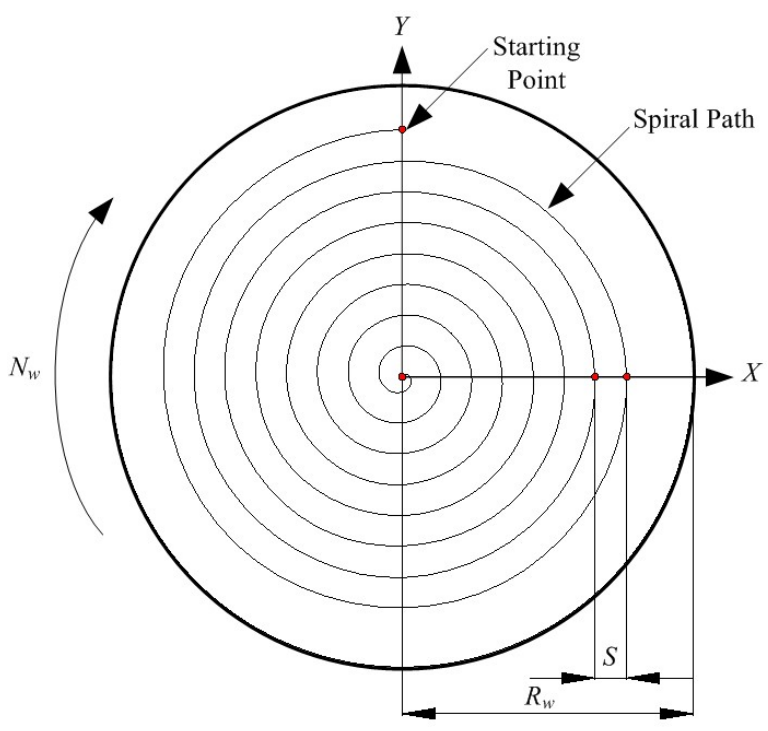

(b)

Fig. 1. Schematic of surface generation in grinding operation 


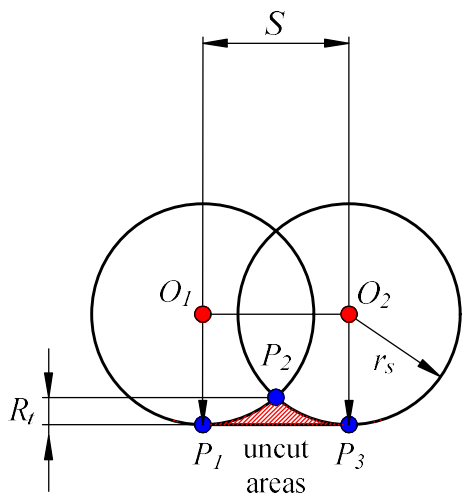

(a)

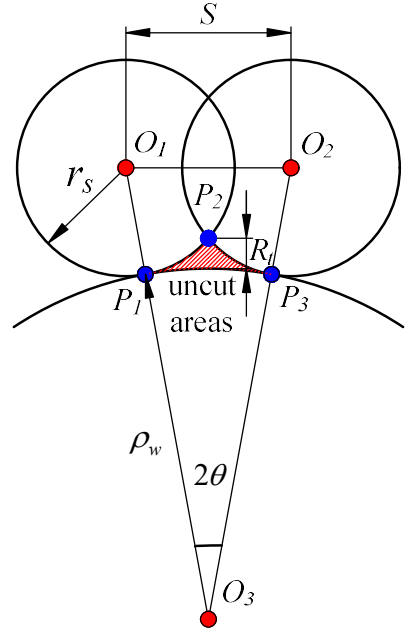

(b)

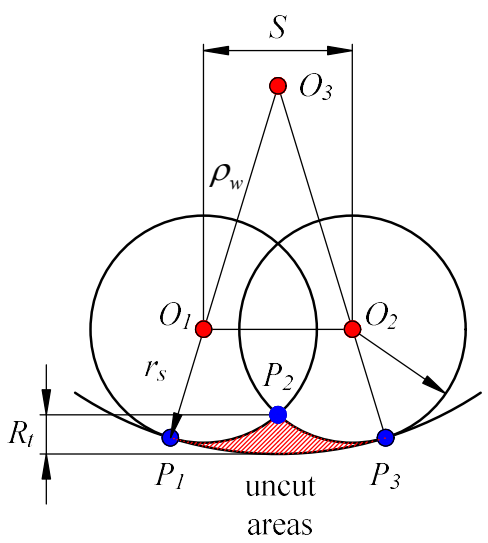

(c)

Fig. 2. Scallop height generation in ultra-precision grinding (a) flat surface (b) convex surface (c) concave surface

For a given allowable tolerance for the scallop height in machining flat surface, the path interval can be determined according to the geometric relation as shown in Fig. 2 (a) as follows:

$$
\begin{aligned}
& r_{s}^{2}=\left(\frac{S}{2}\right)^{2}+\left(r_{s}-R_{t}\right)^{2} \\
& S=\sqrt{r_{s}^{2}-\left(r_{s}-R_{t}\right)^{2}}
\end{aligned}
$$

where $r_{s}$ is the nose radius of the grinding wheel

$S$ is the path interval

In machining convex surface, the path interval can be derived as:

$$
S=\frac{\rho_{w}}{\left(\rho_{w}+R_{t}\right)\left(\rho_{w}+r_{s}\right)} \sqrt{2\left[\left(\rho_{w}+r_{s}\right)^{2}+r_{s}^{2}\right]\left(\rho_{w}+R_{t}\right)^{2}-\left[\left(\rho_{w}+r_{s}\right)^{2}-r_{s}^{2}\right]^{2}-\left(\rho_{w}+R_{t}\right)^{4}}
$$

where $\rho_{w}$ is the curvature radius

$S$ is the path interval

$R_{t}$ is the scallopheight

In machining concave surface, the path interval can be obtained as follows:

$$
S=\frac{\rho_{w}}{\left(\rho_{w}-R_{t}\right)\left(\rho_{w}+r_{s}\right)} \sqrt{2\left[\left(\rho_{w}+r_{s}\right)^{2}+r_{s}^{2}\right]\left(\rho_{w}-R_{t}\right)^{2}-\left[\left(\rho_{w}+r_{s}\right)^{2}-r_{s}^{2}\right]^{2}-\left(\rho_{w}-R_{t}\right)^{4}}
$$

According to the geometric relationship between the machining curved surface as shown in Fig 2(b), the circle for scallopheight in machining convex surface can be derived as: 


$$
\left[x-\left(\rho_{w}+r_{s}\right) \cos \theta\right]^{2}+\left[y-\left(\rho_{w}+r_{s}\right) \sin \theta\right]^{2}=r_{s}^{2}
$$

where $\cos \theta=\frac{\sqrt{\rho_{w}{ }^{2}-\left(\frac{S^{2}}{2}\right)}}{\rho_{w}}, \quad \sin \theta=\frac{S}{2 \rho_{w}}, S=\frac{V_{f}}{N_{w}}$

To obtain the maximum scallop-height, y equals to 0 , the intersecting point can be expressed as:

$$
\begin{aligned}
& {\left[x-\left(\frac{\rho_{w}+r_{s}}{\rho_{w}}\right) \sqrt{\rho_{w}{ }^{2}-\left(\frac{S^{2}}{2}\right)}\right]^{2}+\left[\left(\rho_{w}+r_{s}\right) \sqrt{\rho_{w}{ }^{2}-\left(\frac{S^{2}}{2}\right)}\right]^{2}=r_{s}^{2}} \\
& x=\left(\frac{\rho_{w}+r_{s}}{\rho_{w}}\right) \sqrt{\rho_{w}{ }^{2}-\left(\frac{S^{2}}{2}\right)}-\sqrt{r_{s}{ }^{2}-\left(\frac{\left(\rho_{w}+r_{s}\right) S}{2 \rho_{w}}\right)^{2}}
\end{aligned}
$$

Since $R_{t}=x-\rho_{w}, S=\frac{V_{f}}{N_{w}}$ the scallop-height $R_{t}$ can be determined as:

$$
R_{t}=\left(\rho_{w}+r_{s}\right) \sqrt{1-\left(\frac{V_{f}^{2}}{2 \rho_{w} N_{w}^{2}}\right)}-\sqrt{r_{s}^{2}-\left(\frac{\left(\rho_{w}+r_{s}\right) V_{f}}{2 \rho_{w} N_{w}}\right)^{2}}-\rho_{w}
$$

Feed speed $\left(V_{f}\right)$ for machining convex surface can be calculated as:

$$
V_{f}=\frac{\rho_{w} N_{w}}{\left(\rho_{w}+R_{t}\right)\left(\rho_{w}+r_{s}\right)} \sqrt{2\left[\left(\rho_{w}+r_{s}\right)^{2}+r_{s}^{2}\right]\left(\rho_{w}+R_{t}\right)^{2}-\left[\left(\rho_{w}+r_{s}\right)^{2}-r_{s}^{2}\right]^{2}-\left(\rho_{w}+R_{t}\right)^{4}}
$$

In the same way, for concave surface as shown in Fig 2(b), the scallop-height $R_{t}$ can be determined as:

$$
R_{t}=\rho_{w}-\left(\rho_{w}-r_{s}\right) \sqrt{1-\left(\frac{V_{f}^{2}}{2 \rho_{w} N_{w}^{2}}\right)^{2}}-\sqrt{r_{s}^{2}-\left(\frac{\left(\rho_{w}-r_{s}\right) V_{f}}{2 \rho_{w} N_{w}}\right)^{2}}
$$

Feed speed $\left(V_{f}\right)$ for machining concave surface can be calculated as:

$$
V_{f}=\frac{\rho_{w} N_{w}}{\left(\rho_{w}-R_{t}\right)\left(\rho_{w}+r_{s}\right)} \sqrt{2\left[\left(\rho_{w}+r_{s}\right)^{2}+r_{s}^{2}\right]\left(\rho_{w}-R_{t}\right)^{2}-\left[\left(\rho_{w}+r_{s}\right)^{2}-r_{s}^{2}\right]^{2}-\left(\rho_{w}-R_{t}\right)^{4}}
$$

In order to obtain uniform scallop-height, the feed speed for the allowable residual error can be determined according to the Eq. (8) and Eq. (10) under different surface curvatures of the freeform surface in different contact points.

It is due to the fact that the different curvatures of the freeform surface with respect to the different types of surfaces (convex, flat and concave surface) pose a significant difference in scallop-height. Fig 3 describe the influence of curvature variation on scallop-height. Under the constant feed speed, the scallop height is different, which is determined by the curvature. In order to 
discriminate the three different surfaces, the second partial derivative of the designed surface $z=f(r, \theta)$ in different radical sections can be calculated as shown in Fig. 3 .

$$
z^{\prime \prime}=f^{\prime \prime}(r, \theta)=\frac{\partial^{2} z}{\partial r^{2}}
$$

For convex surface, $z^{\prime \prime}=\frac{\partial^{2} z}{\partial r^{2}}<0$, the flat surface $z^{\prime \prime}=\frac{\partial^{2} z}{\partial r^{2}}=0$, for concave surface $z^{\prime \prime}=\frac{\partial^{2} z}{\partial r^{2}}>0$.

According to the Eq (9) and Eq. (11), the variable feed speed can be calculated. Fig. 4 shows the flow chart of the algorithm for realizing the uniform scallop-height in ultra-precision grinding freeform surfaces.

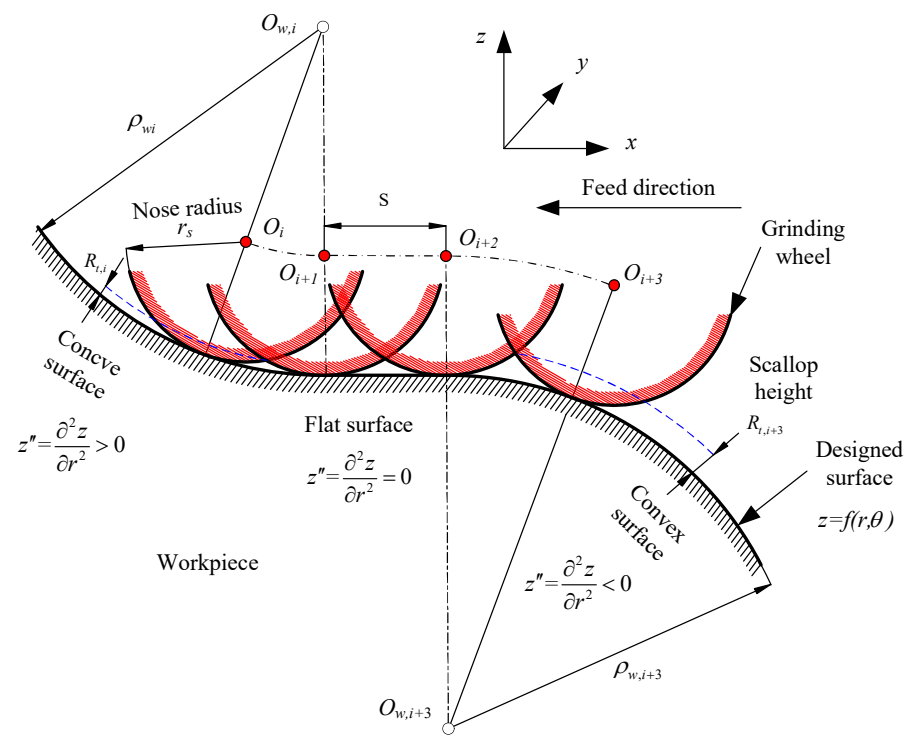

Fig. 3. Computation of the scallop height and discrimination of concave, flat and convex surface in machining

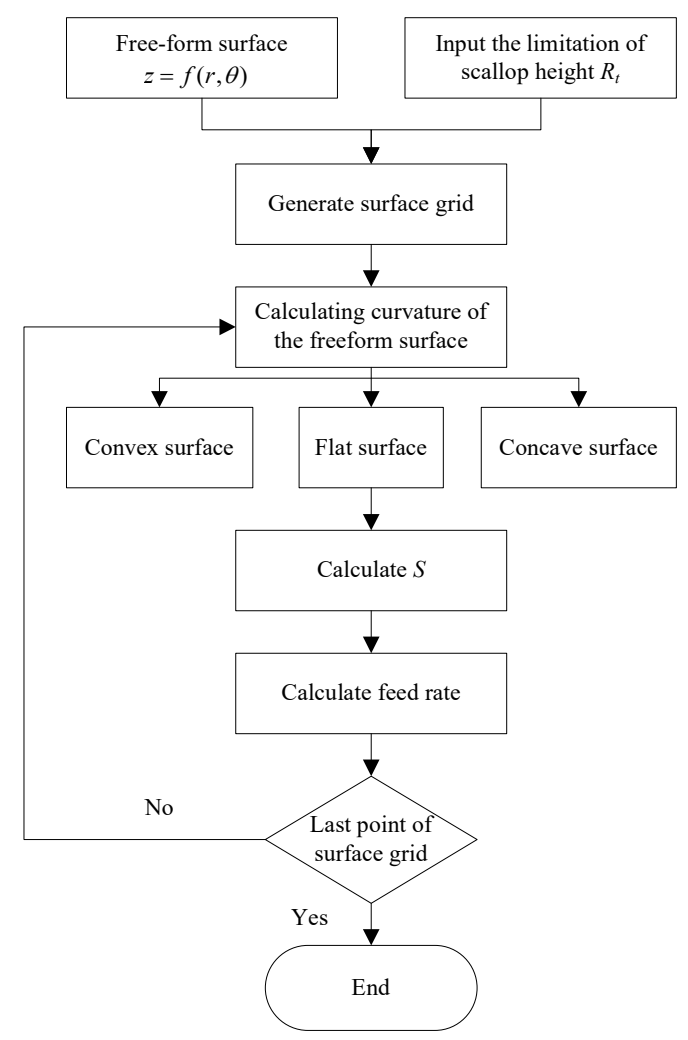

Fig. 4. Flow chart of the tool path generation for realizing the uniform scallop-height machining 


\section{Experimental design and simulation}

The machining freeform surfaces are performed on an ultra-precision grinding machine (Moore Nanotech 450UPL). The grinding machine makes use of a rotational table (B axis) to hold the wheel spindle and the workpiece is mounted on an air bearing, in which, the workpiece spindle rotated and fed over a high-speed spinning wheel to remove excess materials and shape the desired form, as shown in Fig. 5. In the ultra-precision grinding experiments, tungsten carbide (WC) is used as the workpiece material, which is widely used in the fabrication of the optical mold and the machining conditions are summarized in Table 1 . In order to avoid the disturbance of the original surface topography of the workpiece, all workpieces are processed through two steps of rough and fine grinding before grinding experiment, and then the grinding wheel is dressed before machining each workpiece so as to reduce the impact of grinding wheel wear. The non-contact Zygo Laser Interferometer Profiler is used to measure the ground surface topography.

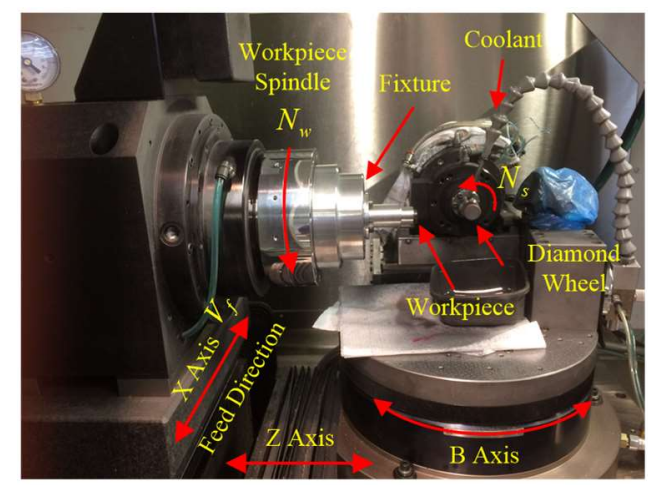

(a)

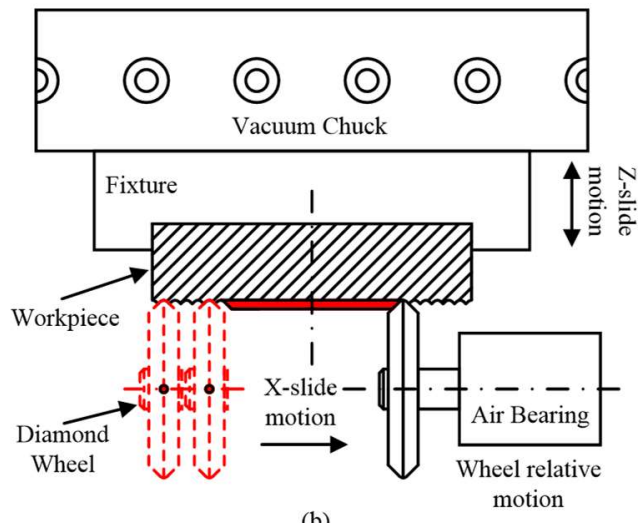

(b)

Fig. 5. Experimental setup for the ultra-precision grinding machine in experiments (a) schematic diagram of the grinding machine (b) layout of the grinding wheel and workpiece

Table 1 Grinding wheel and experimental conditions

\begin{tabular}{ll}
\hline & Resin bonded diamond wheel \\
& Grain size: 500 -grit \\
Diameter: $18 \mathrm{~mm}$ & Thickness: $5 \mathrm{~mm}$ \\
Grinding Wheel & Nose radius: $0.5 \mathrm{~mm}$ \\
& Concentration: $100 \%$ \\
& Structural number: 7 \\
\hline Speed of the grinding wheel $\left(N_{s}\right)(\mathrm{RPM})$ & 40000 \\
Speed of the workpiece $\left(N_{w}\right)(\mathrm{RPM})$ & 200 \\
Feed rate $\left(V_{f}\right)(\mathrm{mm}$ per min) & 5 \\
Depth of cut $(H)(\mu \mathrm{m})$ & 10 \\
\hline Coolant & CLAIRSOL 330 \\
\hline
\end{tabular}

In this experiment, two types of sinusoidal surface are machined, they are annular sinusoidal surface and single sinusoidal surface. In cartesian coordinate system, they can be expressed in Eq.(13) and Eq.(14) respectively. According to Eq.(13) and Eq.(14) and setting $A=50 \mu m, \lambda=3 \mathrm{~mm}$ and $\varphi=90^{\circ}$, the simulated sinusoidal surfaces are shown in Fig. 6(a) and Fig. 6(b).

$$
\begin{aligned}
& z=f(x, y)=A \sin \left(\frac{2 \pi x}{\lambda}+\varphi\right) \\
& z=f(x, y)=A \sin \left(\frac{2 \pi \sqrt{x^{2}+y^{2}}}{\lambda}+\varphi\right)
\end{aligned}
$$

where $A$ is the amplitude of sinusoidal surface, $\lambda$ is the wave length of sinusoidal surface, $\varphi$ is phase angle. 


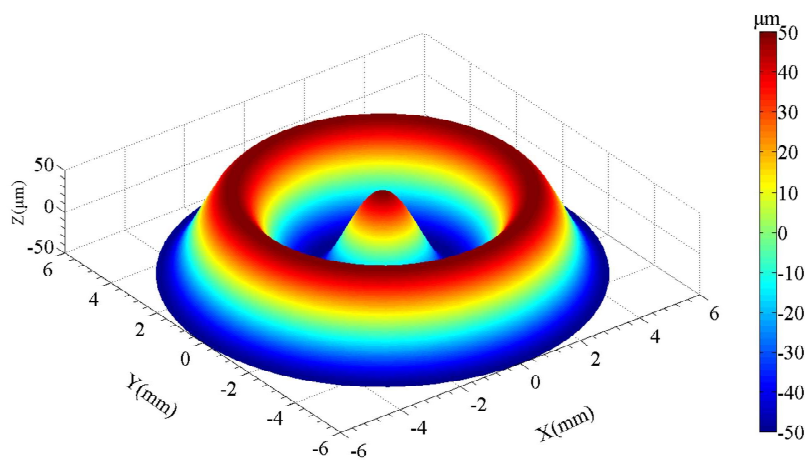

(a)

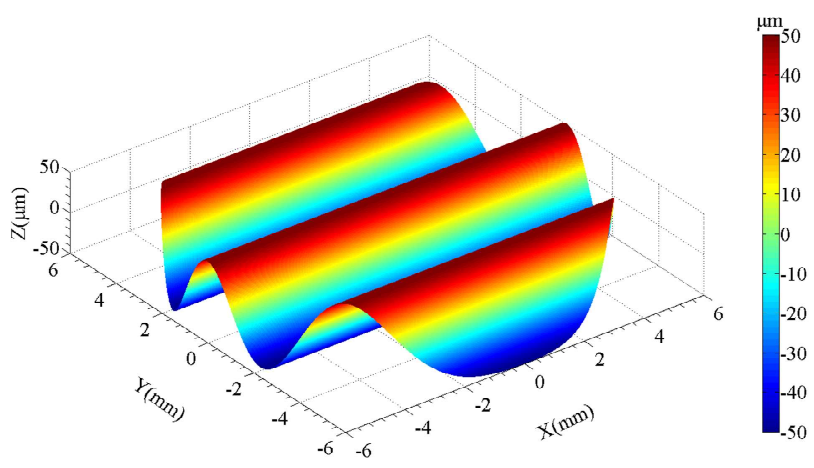

(b)

Fig. 6. Simulated sinusoidal surfaces (a) annular sinusoidal surface and (b) single sinusoidal surface

The allowable scallop height is setting at $1 \mu \mathrm{m}$ and $2 \mu \mathrm{m}$ for single sinusoidal surface and annular sinusoidal surface respectively. The grinding wheel nose radius is $0.5 \mathrm{~mm}$. According to Eq.(13) and Eq.(14), the tool path can be determined and Fig. 7 shows the estimated 3D tool path for machining the two sinusoidal surfaces. In order to observe the tool path clearly, the tool path intervals are enlarged.

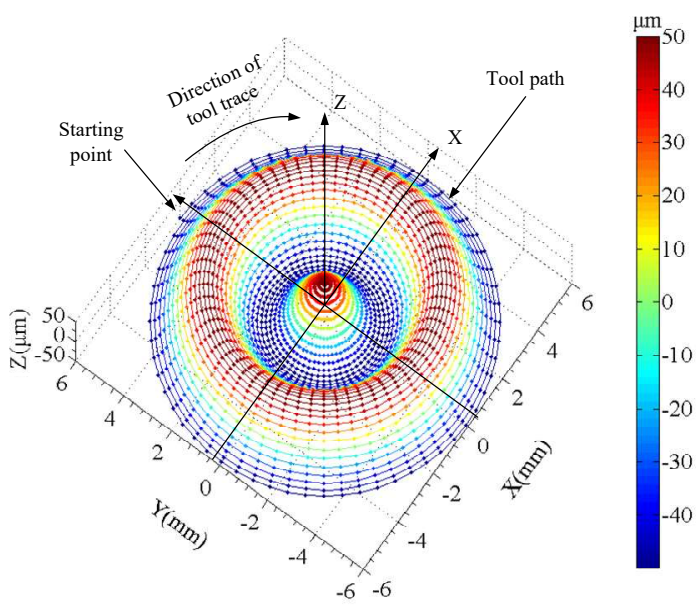

(a)

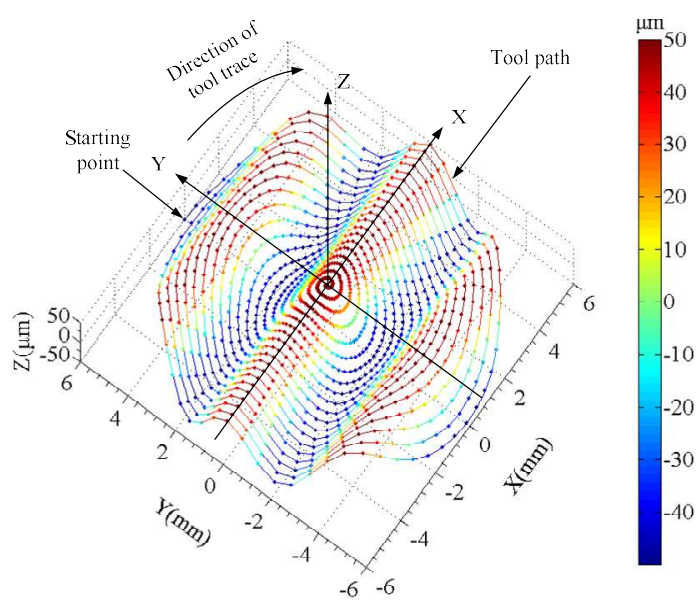

(b)

Fig. 7. Simulated tool path sinusoidal surfaces (a) annular sinusoidal surface and (b) single sinusoidal surface $\left(N_{w}=200 \mathrm{rpm}, N_{s}=40000 \mathrm{rpm}, H=10 \mu \mathrm{m}\right)$

The machined sinusoidal surfaces were measured by using a non-contact laser interferometer profiler apparatus. Fig. 8 shows the sinusoidal surfaces machined by three-axis ultra-precision grinding machine. The result shows that the form error is larger for machining non-rotational symmetric surface than that for rotational symmetric surface, which may be caused by the machine dynamics errors. For rotational symmetric surface, the cross section profiles at different angular positions are the same. However, the cross section of the surface is dependent on the angular position the non-rotational symmetric surface, which is susceptible to the tool motion control errors in machining. 


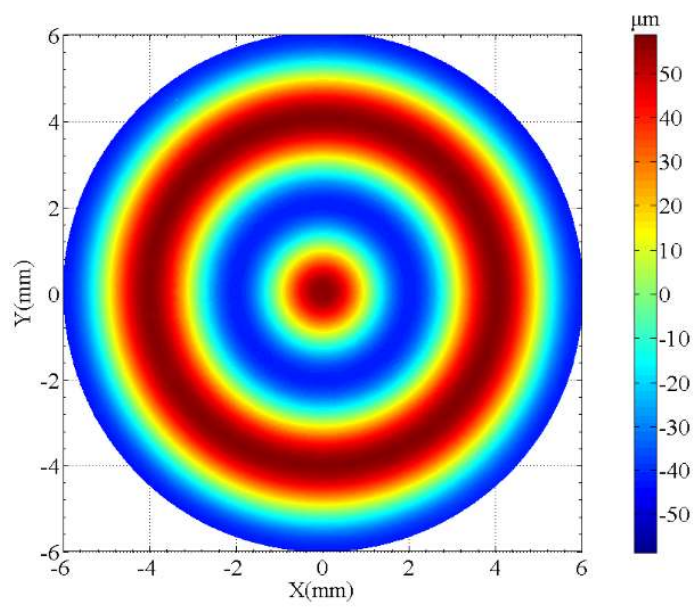

(a)

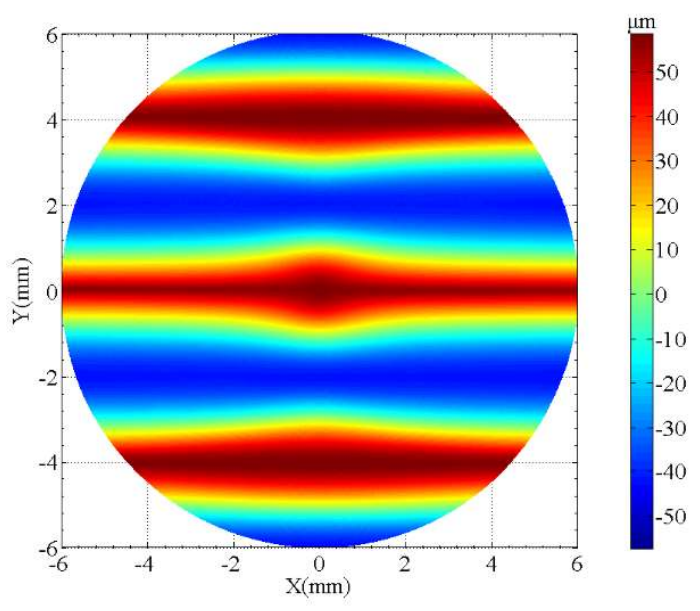

(b)

Fig. 8. Measured surfaces (a) annular sinusoidal surface and (b) single sinusoidal surface $\left(N_{w}=200 \mathrm{rpm}, N_{s}=40000 \mathrm{rpm}, H=10 \mu \mathrm{m}\right)$

The form accuracy in machining freeform surfaces is an important indicator to determine the functional performance in ultraprecision grinding. The deviation of whole ground surface and distribution of the form errors should be verified to evaluate machining performance. The main purpose of the surface matching between the measured surface and the designed surface is to make the two surfaces as close as possible. In order to improve the matching accuracy, it is necessary to continuously iterate and adjust again and again to find the optimal spatial position of the measured surface.

There are two parts in the matching process. One part is the translation operation, which can be represented by the matrix $T\left(t_{x}, t_{y}, t_{z}\right)$, the other part is the rotation process, which can be represented by the matrix $R(\alpha, \beta, \gamma)$. The whole transformation calculation process is

$$
M=T\left(t_{x}, t_{y}, t_{z}\right) \cdot R(\alpha, \beta, \gamma)
$$

The translation matric can be expressed as:

$$
T\left(t_{x}, t_{y}, t_{z}\right)=\left[\begin{array}{cccc}
1 & 0 & 0 & t_{x} \\
0 & 1 & 0 & t_{y} \\
0 & 0 & 1 & t_{z} \\
0 & 0 & 0 & 1
\end{array}\right]
$$

where, $t_{x}, t_{y}$ and $t_{z}$ represent translational transformation in $x, y$ and $z$ direction

Rotation transformation matrix can be expressed as:

$$
\begin{aligned}
& R(\alpha, \beta, \gamma)=R_{z}(\gamma) \cdot R_{y}(\beta) R_{x}(\alpha) \\
& \quad=\left[\begin{array}{cccc}
\cos \gamma \cos \beta & \cos \gamma \sin \beta \sin \alpha-\sin \gamma \cos \alpha & \sin \gamma \sin \alpha+\cos \gamma \sin \beta \cos \alpha & 0 \\
\sin \gamma \cos \beta & \cos \gamma \cos \alpha+\sin \gamma \sin \beta \sin \alpha & \sin \gamma \sin \beta \cos \alpha-\cos \gamma \sin \alpha & 0 \\
-\sin \beta & \cos \beta \sin \alpha & \cos \beta \cos \alpha & 0 \\
0 & 0 & 0 & 1
\end{array}\right]
\end{aligned}
$$

where, $\alpha, \beta$ and $\gamma$ represent the rotation angle of the measured surface around $x, y$ and $z$ axis

According to Eq. (15) - Eq. (17), the spatial coordinate transformation matrix can be expressed as:

$$
M=\left[\begin{array}{cccc}
\cos \gamma \cos \beta & \cos \gamma \sin \beta \sin \alpha-\sin \gamma \cos \alpha & \sin \gamma \sin \alpha+\cos \gamma \sin \beta \cos \alpha & t_{x} \\
\sin \gamma \cos \beta & \cos \gamma \cos \alpha+\sin \gamma \sin \beta \sin \alpha & \sin \gamma \sin \beta \cos \alpha-\cos \gamma \sin \alpha & t_{y} \\
-\sin \beta & \cos \beta \sin \alpha & \cos \beta \cos \alpha & t_{z} \\
0 & 0 & 0 & 1
\end{array}\right]
$$


In Eq. (18), there are six parameters need to be solved, rotation angle $\alpha, \beta$ and $\gamma$ and the translation distance $t_{x}, t_{y}$ and $t_{z}$. In order to figure out these six unknown parameters, the transformation matrix can satisfy the following equation:

$$
\min \left[F_{j}(T)\right]=\min \left[\sum_{i=1}^{i=m}\left|T_{j} Q_{i j}-P_{i j}\right|^{2}\right]
$$

where, $Q_{i j}=\left[x_{i j}, y_{i j}, z_{i j}, 1\right]^{T}$ Is the point on the measured surface, $P_{i j}=\left[x_{i j}^{\prime}, y_{i j}^{\prime}, z_{i j}^{\prime}, 1\right]^{T}$ is the closest point to the measured surface on the designed surface, $j$ is the number of iterations.

Substitute the data points of the measured surface into Eq. (19), then take partial derivative and set it equal to 0

$$
\frac{\partial}{\partial T}\left[F_{j}(T)\right]=2 \sum_{i=1}^{i=m}\left[\left|T_{j} Q_{i j}-P_{i j}\right| \frac{\partial}{\partial T}\left(\left|T_{j} Q_{i j}-P_{i j}\right|\right)\right]=0
$$

In order to further verify the deviation between the designed sinusoidal surfaces and measured surfaces quantitatively, the matching of the simulated surface and the measured surface is conducted, in which the measured points for surface and the data for the design surface are transferred into the same coordinate system by a spatial rotation and translation. Fig. 9 shows the evaluated matching errors for the machining of different sinusoidal surface. It shows that larger errors for machining single sinusoidal surface.

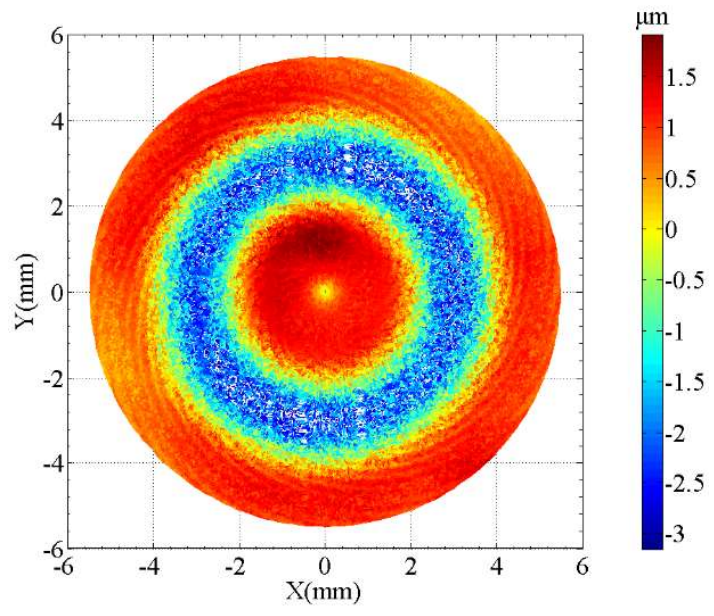

(a)

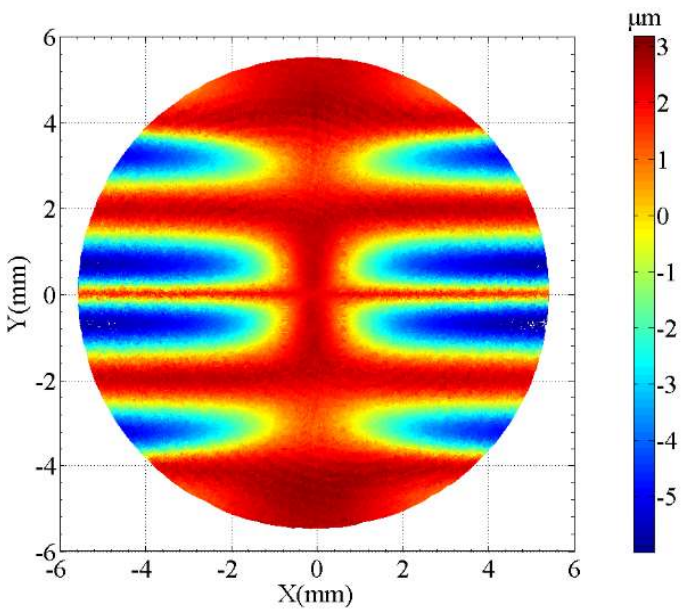

(b)

Fig. 9. Matching error map for machining (a) annular sinusoidal surface and (b) single sinusoidal surface $\quad\left(N_{w}=200 \mathrm{rpm}, N_{s}=40000 \mathrm{rpm}, H=10 \mu \mathrm{m}\right)$

It is found that the scallop-height is uneven in the conventional tool path control method, which resulted from the influence of the changed curvature of workpiece surface. On the relatively flat area, the scallop-height is about $1 \mu$ m. However, on the area with small curvature radius, surface scallop-height is larger, the scallop-height increased to $2.5 \mu \mathrm{m}$, as shown in Fig. 10 .

Fig. 11 shows the measured cross section profiles of sinusoidal surface and scallop-height is about $1 \mu \mathrm{m}$ in grinding annular sinusoidal surface and single sinusoidal surface $(X=0)$. The scallop-height both for annular sinusoidal surface and single sinusoidal surface are kept uniform approximately. At the same time, the peaks on the maximum of the central sinusoid is caused the tool setting error. 


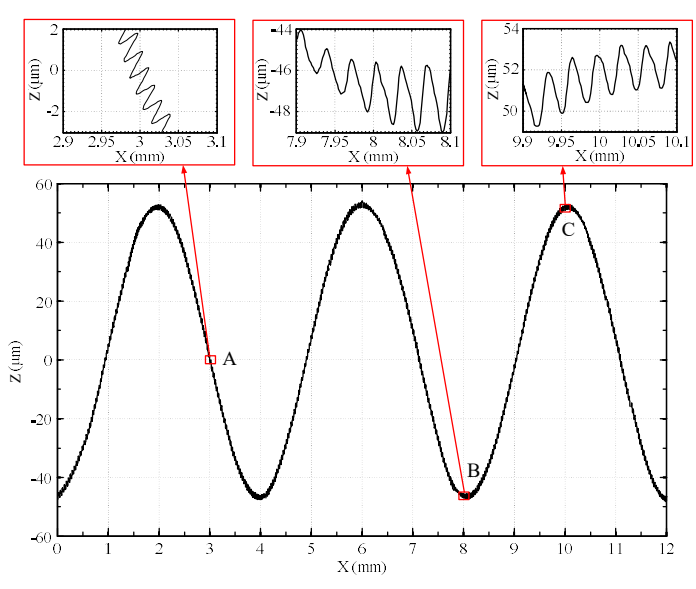

Fig 10. Scallop height for cross section profiles generated in machining annular sinusoidal surface by adopting control strategy of constant feed speed $\left(N_{w}=200\right.$ $\left.\mathrm{rpm}, N_{s}=40000 \mathrm{rpm}, H=10 \mu \mathrm{m}, V_{f}=5 \mathrm{~mm} / \mathrm{min}\right)$

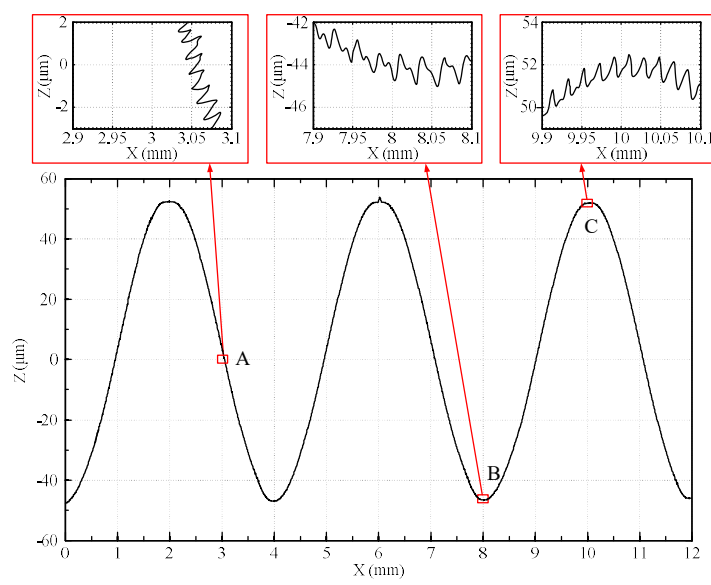

(a)

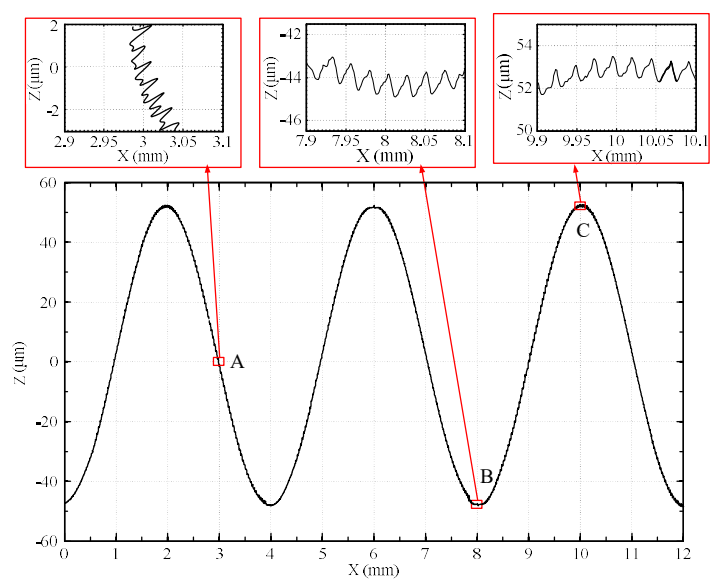

(b)

Fig. 11. Measured cross section profiles by adopting control strategy of uniform scallop height method (a) annular sinusoidal surface and (b) single sinusoidal surface $\left(N_{w}=200 \mathrm{rpm}, N_{s}=40000 \mathrm{rpm}, H=10 \mu \mathrm{m}\right)$

Table 2 shows a comparison of the arithmetic roughness of this two types of freeform surface with respect to different areas corresponding to the Fig 10. Each workpiece is machined for 3 times and then calculated the average value for $P V$ value. It is found that the $P V$ value approximately keep uniform in machining those two freeform surfaces respectively and the matching error for machining single sinusoidal surface in terms of root-mean-square value $(R M S$ is $0.182 \mu \mathrm{m}$ is significantly larger than that of machining annual sinusoidal surface (i.e. $R M S=0.108 \mu \mathrm{m}$ ).

Table 2 Machining results for the arithmetic roughness $R a$ and the root mean squared value ( $R M S$ )of matching errors

\begin{tabular}{ccccc}
\hline Surface type & \multicolumn{1}{c}{$P V$ value $(\mu \mathrm{m})$} & \multicolumn{2}{c}{ Root-mean-square value } \\
\cline { 2 - 4 } & $\mathrm{A}$ & $\mathrm{B}$ & $\mathrm{C} M S(\mu \mathrm{m})$ & 0.108 \\
\hline Annular sinusoidal surface & 1.19 & 1.21 & 1.26 & 0.182 \\
Single sinusoidal surface & 1.22 & 1.17 & 1.24 & 0 \\
\hline
\end{tabular}

\section{Conclusion}

In this paper, a novel method for the optimization of tool path to achieve uniform scallop height in ultra-precision grinding freeform surface is presented. , It can be used to realize uniform machined surface condition. The theoretical models both for the uniform scallop height in grinding convex surface and concave surface are developed. The model predicted results for the machined surfaces agree well with that of the experimental results. For machining freeform surface, the scallop height is significantly different from machining flat surface, which is more complex and has a strong correlation to the curvature of the surface. For different curvature radii in conventional grinding, the scallop height is ununiformed, the larger curvature radius results in higher scallop height which adversely affecting the surface quality. This model provides an effect way to overcome the uneven surface residual height by changing the feed speed of the grinding wheel. In addition, there is the larger surface form errors for machining non- 
rotational symmetric surface than that of rotational symmetric surface.

\section{Acknowledgements}

The work was supported by a PhD studentship (project account code: RU3K) and a MPhil studentship (project account code: RU7J) from The Hong Kong Polytechnic University. This research work was also supported by the State Key Basic Research and Development Program, China (973 program, Grant no. 2011CB 013202) and Guangdong Provincial Department of Science and Technology, Guangdong, P.R. China for The Introduction of Innovative R\&D Team Program of Guangdong Province (Project no.:201001G0104781202).

\section{References}

[1] Brinksmeier E, Glabe R, Flucke C (2008) Manufacturing of molds for replication of micro cube corner retroreflectors. Production Engineering 2(1):33-38.

[2] Lazoglu I, Manav C, Murtezaoglu Y (2009) Tool path optimization for free form surface machining. CIRP Annals - Manufacturing Technology 58(1):101-104.

[3] Lasemi A, Xue DY; Gu PH (2010) Recent development in CNC machining of freeform surfaces: A state-of-the-art review. Computer-Aided Design 42(7):641654.

[4] Lasemi A, Xue DY; Gu PH (2014) Tool path re-planning in free-form surface machining for compensation of process-related errors. International Journal of Production Research 52(20):5913-5931.

[5] Fang FZ, Zhang XD, Weckenmann A et al (2013) Manufacturing and measurement of freeform optics. CIRP Annals-Manufacturing Technology 62(2):823846.

[6] Brinksmeier E, Mutlugünes Y, Klocke FJC et al (2010) Ultra-precision grinding. CIRP Annals-Manufacturing Technology 59(2):652-671.

[7] Li H, Remus TF, Feng HY (2007) An improved tool path discretization method for five-axis sculptured surface machining. International Journal of Advanced Manufacturing Technology 33(9-10):994-1000.

[8] Lin Z, Fu J, Shen H, et al (2014) A generic uniform scallop tool path generation method for five-axis machining of freeform surface. Computer-Aided Design 56:120-132.

[9] Gong H, Wang Y, Song Let al (2015) Spiral tool path generation for diamond turning optical freeform surfaces of quasi-revolution. Computer-Aided Design 59:15-22.

[10] Yu DP, Gan SW, Wong YS et al (2012) Optimized tool path generation for fast tool servo diamond turning of micro-structured surfaces. The International Journal of Advanced Manufacturing Technology 63(9):1137-1152.

[11] Kwok TC, Cheung CF, Kong LB et al (2010) Analysis of surface generation in ultra-precision machining with a fast tool servo. Proceedings of the Institution of Mechanical Engineers, Part B: Journal of Engineering Manufacture 224(9):1351-1367.

[12] Yu DP, Hong GS; Wong YS (2012) Profile error compensation in fast tool servo diamond turning of micro-structured surfaces. International Journal of Machine Tools and Manufacture 52(1):13-23.

[13] Kong L B, Cheung C F (2012) Modeling and characterization of surface generation in fast tool servo machining of microlens arrays. Computers and Industrial Engineering 63(4):957-970.

[14] Zhou M, Zhang HJ, Chen SJ (2010) Study on diamond cutting of nonrationally symmetric microstructured surfaces with fast tool servo. Materials and Manufacturing Processes 25(6):488-494. 